\title{
Brain-derived neurotrophic factor, but not body weight, correlated with a reduction in depression scale scores in men with metabolic syndrome: a prospective weight-reduction study
}

I-Te Lee ${ }^{1,2,3}$, Chia-Po Fu' ${ }^{1}$, Wen-Jane Lee ${ }^{4}$, Kae-Woei Liang ${ }^{3,5}$, Shih-Yi Lin ${ }^{1,3}$, Chu-Jen Wan ${ }^{6}$ and Wayne Huey-Herng Sheu ${ }^{1,2,3,7^{*}}$

\begin{abstract}
Background: Obesity, a critical component of metabolic syndrome (MetS), is associated with depression. Deficiency of brain-derived neurotrophic factor (BDNF) is involved in the mechanism of depression. We hypothesized that weight reduction would improve depressive symptoms via increasing BDNF levels in obese men.

Methods: Male adults with obesity were enrolled in a weight-reduction program for twelve weeks. All subjects underwent daily caloric restriction and an exercise program which was regularly assessed in group classes. Fasting blood samples and Zung Self-Rating Depression Scale (Zung SDS) scores were collected for assessments before and after the study.

Results: A total of 36 subjects completed this program. The average reduction in body weight was $8.4 \pm 5.1 \mathrm{~kg}$ $(8.8 \pm 5.1 \%, P<0.001)$. Fasting serum BDNF significantly increased after the study (from $40.4 \pm 7.8$ to $46.9 \pm 8.9 \mathrm{ng} / \mathrm{ml}$, $\mathrm{P}<0.001)$. However, the depression symptoms, as assessed by the Zung Self-Rating Depression Scale (Zung SDS), did not reduce significantly $(P=0.486)$. Divided into subgroups based on changes in BDNF, Zung SDS scores were significantly reduced in subjects with greater BDNF increase than in those with minor BDNF change $(-3.9 \pm 6.2$ vs. $2.3 \pm 6.7, P=0.009)$. The increased percentage of BDNF was inversely correlated with the change in Zung SDS $(r=-0.380, P=0.022)$. Multivariate regression analysis showed that reduction in BDNF was independently associated with change in Zung SDS (95\% confidence interval -0.315 to $-0.052, \mathrm{P}=0.008$ ).
\end{abstract}

Conclusion: Zung SDS only significantly improved in men with increased fasting BDNF levels after a lifestyle intervention. Trial registration: (NCT01065753, ClinicalTrials.gov)

Keywords: Exercise, Lifestyle intervention, Obesity, Zung self-rating depression scale

\section{Introduction}

Metabolic syndrome (MetS), a cluster of risk factors for cardiovascular disease, is associated with several chronic diseases and has become an important public health concern due to its high prevalence [1-3]. Obesity is considered a critical target for treatment due to its

\footnotetext{
* Correspondence: whhsheu@vghtc.gov.tw

1 Division of Endocrinology and Metabolism, Department of Internal Medicine, Taichung Veterans General Hospital, No. 1650, Section 4, Taiwan Boulevard, Taichung 40705, Taiwan

${ }^{2}$ School of Medicine, Chung Shan Medical University, Taichung, Taiwan

Full list of author information is available at the end of the article
}

pathophysiological role in MetS [4-6]. Weight reduction by dietary and exercise intervention can prevent several sequential complications of MetS [7-9].

Adult obesity is also associated with intellectual disabilities [10]. Decreased hippocampal volume and advanced brain atrophy have been reported in subjects with central obesity [11]. Furthermore, MetS could predict cognitive impairment in prospective studies [12,13]. MetS is clearly associated with dysfunction of the central nervous system; however, the underlying factors contributing to the pathogenesis of the central nervous system are not well understood. It was postulated that inflammation

\section{() BioMed Central}


was associated with cognitive dysfunction in MetS [12-14]. Several studies have also suggested that some peripheral signals, crossing the blood brain barrier, may be involved in neuroprotective pathways [15-17].

Brain-derived neurotrophic factor (BDNF), an important neurotrophin in the development of neurons and the regulation of synaptic activities, exists not only in the central nervous system but also in the peripheral blood with a positive correlation [18-21]. The process of learning and memory formation are associated with the activation of tyrosine receptor kinase $B(\operatorname{TrkB})$ through the binding of BDNF [22]. BDNF has been reported to be associated with depression, and the severity of depression might be affected by changes in BDNF after antidepressant treatment $[23,24]$.

Furthermore, BDNF helps maintain the energy homeostasis that suppresses food intake and increases energy expenditure $[25,26]$. Circulating BDNF was reported to be increased in obese women, and high BDNF levels were observed in subjects with MetS [27-29]. Conversely, low BDNF concentrations were also observed in subjects with obesity, MetS or diabetes [30,31]. Martin et al. [32] reported improved cognitive function and increased circulating BDNF in rats undergoing energy restriction. To examine the hypothesis that an increase in circulating BDNF concentration can improve central nervous symptoms in men during weight reduction, a prospective study was conducted to assess BDNF and depression score in men with MetS after a lifestyle intervention.

\section{Methods}

\section{Subjects}

This study was conducted in the Division of Endocrinology and Metabolism at Taichung Veterans General Hospital. The inclusion criteria were men with MetS as defined by the International Diabetes Federation (IDF), who fulfilled the following conditions: central obesity with a waist circumference greater than $90 \mathrm{~cm}$, plus two or more of the following four components: (1) triglyceride equal to or greater than $150 \mathrm{mg} / \mathrm{dL}(1.7 \mathrm{mmol} / \mathrm{L}),(2)$ high-density lipoprotein (HDL) cholesterol less than $40 \mathrm{mg} / \mathrm{dL}(1.0 \mathrm{mmol} / \mathrm{L})$, (3) blood pressure equal to or greater than $130 / 85 \mathrm{mmHg}$ or using antihypertensive medications and (4) fasting glucose equal to or greater than $100 \mathrm{mg} / \mathrm{dL}(5.6 \mathrm{mmol} / \mathrm{L})$ [4]. Exclusion criteria were: (1) aged under 20 or over 75 years, (2) history of diabetes or taking anti-diabetic medications, (3) history of psychological disorders or medications for schizophrenia or bipolar disorder, (4) endocrine diseases such as thyroid or adrenal disorders, (5) acute or chronic renal diseases with serum creatinine levels greater than $200 \mathrm{mmol} / \mathrm{L}$, (6) alanine aminotransferase or aspartate aminotransferase levels three times greater than the normal upper limit, or liver cirrhosis, (7) acute or chronic infectious diseases, (8) severe systemic diseases such as malignant or immune disorders, (9) addiction to alcohol or drugs, (10) taking any medication which changes body weight, such as steroid, (11) changes in medications for hypertension, hyperlipidemia, anti-platelet or anti-inflammation in the past month, (12) limitations to following the regular dietary and exercise intervention based on clinical judgment or the participant's personal reasons.

\section{Procedure}

All the enrolled subjects took part in a scheduled twelve-week weight-reduction program. Each subject received instructions from a registered dietitian on how to maintain a $1200 \mathrm{Kcal} /$ day diet, divided into $300 \mathrm{Kcal}$ at breakfast, $400 \mathrm{Kcal}$ at lunch and $500 \mathrm{Kcal}$ at dinner. Subjects were required to attend eight classes of group training in lifestyle change. The content of each three-hour class included: (1) assessment of body weight and diet diaries by the dietitian, (2) an educational program for diet control, exercise promotion and target setting, (3) a discussion among the participants, the dietitian and doctors specializing in cardiology or endocrinology, and (4) a 50-minute practice session with moderate aerobic exercise under the supervision of trained instructors and with the attendance of doctors. A reduction of $10 \%$ in basal body weight was planned and no medication changes were allowed during the study. The study was approved by the Institutional Review Board of Taichung Veterans General Hospital and written informed consent was provided by all participants (NCT number: 01065753).

\section{Measurements}

Overnight fasting blood samples were collected at baseline and at the end of the study for measurements of glucose, insulin, lipids, liver enzymes, creatinine, $\mathrm{C}$-reactive protein (CRP) and BDNF. Study subjects were assessed using the Zung Self-Rating Depression Scale (Zung SDS). There were 20 items on the depression questionnaire, either positive or negative, which the study subjects were required to grade on a scale of 1 to 4 . The severity score was calculated by formula conversion [33].

Glucose, creatinine, triglyceride, cholesterol and liver enzymes were measured by commercial kits (Beckman Coulter, Fullerton, USA). Insulin, HDL cholesterol and low-density lipoprotein (LDL) cholesterol levels were also measured by commercial kits (Roche Diagnostics GmbH, Mannheim, Germany). For quantitative evaluation of insulin resistance, the homeostasis model assessment of insulin resistance (HOMA-IR) index was calculated using the following equation: fasting insulin $(\mu \mathrm{IU} / \mathrm{mL}) *$ fasting glucose $(\mathrm{mmol} / \mathrm{L}) / 22.5$ [34]. CRP was measured by the immunochemical assay of purified Duck $\operatorname{IgY}(\Delta \mathrm{Fc})$ antibodies (Good Biotech Corp., Taichung, Taiwan); the mean 
intra-assay and inter-assay CVs for CRP were $1.4 \%$ and $1.4 \%$, with an analytical sensitivity of $0.1 \mathrm{mg} / \mathrm{L}$. Human BDNF was measured by a commercially available immunoassay kit (R \& D Systems, Minneapolis, USA), and the mean intra-assay and inter-assay CVs for BDNF were $4.1 \%$ and $9.0 \%$, respectively, with an analytical sensitivity of $0.02 \mathrm{ng} / \mathrm{mL}$. There was no significant cross-reactivity or interference with nerve growth factor, neurotrophin-3 and neurotrophin-4 prepared at a concentration of $50 \mathrm{ng} / \mathrm{mL}$ in a BDNF control.

\section{Statistics}

All descriptive data were presented as mean \pm standard deviation (SD). Statistical analyses were conducted with the non-parametric Wilcoxon Signed Rank test to compare the difference before and after intervention. The relationship between the change in Zung SDS and the associated risk factors was determined by Spearman's correlation. A Mann-Whitney test was used to detect the difference between the two groups. Multivariate linear regression analysis was employed to analyze the factors associated with the change in Zung SDS. Statistical analyses were performed using SPSS 12.0 (Chicago, IL, USA).

\section{Results}

Of the 40 subjects with MetS enrolled for the study, 36 subjects completed the weight-reduction program. The average weight was significantly reduced by $8.4 \pm 5.1 \mathrm{~kg}$ $(8.7 \pm 5.1 \%, \mathrm{P}<0.001)$. The average serum concentration of BDNF was significantly increased at the end of the study (from $40.4 \pm 7.8$ to $46.9 \pm 8.9 \mathrm{ng} / \mathrm{ml}, \mathrm{P}<0.001$ ). However, the Zung SDS did not significantly differ from the baseline by the end of the study (from $37.6 \pm 8.8$ to $36.9 \pm 7.2, \mathrm{P}=0.486)$. To determine the effect of BDNF, all subjects were equally divided into two groups based on the percentage change in BDNF (median of 16.1\%) (Table 1). The baseline fasting insulin $(\mathrm{P}=0.034)$ and HOMA-IR ( $\mathrm{P}=0.029)$ were higher in subjects with a greater BDNF increase than in those with a minor BDNF change. Table 2 shows the characteristics of both groups before and after the study. No significant differences were observed in change of body weight, adipokines, CRP or any of the MetS components between these two groups at the end of the study. Interestingly, significant reduction in Zung SDS in subjects with a greater BDNF increase was found compared to those with a minor BDNF change $(-3.9 \pm 6.2$ vs. $2.3 \pm 6.7, \mathrm{P}=0.008)$. Figure 1 shows a significant correlation between the changes in BDNF and in Zung SDS $(r=-0.380, \mathrm{P}=0.022)$. However, change in body weight or MetS components were not correlated with Zung SDS (Table 3). Based on the regression model, the increase in BDNF was an independent factor for the reduction of Zung SDS, after adjusting for age, insulin resistance, and changes in weight.
Table 1 The baseline data of subjects based on percentage change in BDNF $^{1}$

\begin{tabular}{lccc}
\hline & $\begin{array}{c}\text { Minor BDNF } \\
\text { change } \\
(\mathbf{n}=\mathbf{1 8})\end{array}$ & $\begin{array}{c}\text { Greater BDNF } \\
\text { increase } \\
\mathbf{( n = 1 8 )}\end{array}$ & $\mathbf{P}$ \\
\hline Age (year) & $41 \pm 9$ & $47 \pm 11$ & 0.084 \\
Body weight $(\mathrm{kg})$ & $95.6 \pm 13.8$ & $98.3 \pm 11.4$ & 0.319 \\
BMI (kg/m $\left.{ }^{2}\right)$ & $33.5 \pm 4.2$ & $33.4 \pm 3.6$ & 0.849 \\
Waist circumference $(\mathrm{cm})$ & $108.1 \pm 10.4$ & $110.0 \pm 7.8$ & 0.288 \\
Systolic BP $(\mathrm{mmHg})$ & $129 \pm 16$ & $141 \pm 18$ & 0.059 \\
Diastolic BP $(\mathrm{mmHg})$ & $79 \pm 12$ & $82 \pm 13$ & 0.438 \\
Fasting glucose $(\mathrm{mmol} / \mathrm{L})$ & $5.5 \pm 0.9$ & $5.7 \pm 0.7$ & 0.090 \\
Fasting insulin $(\mu / \mathrm{U} / \mathrm{ml})$ & $15.6 \pm 5.2$ & $22.8 \pm 14.0$ & 0.034 \\
HOMA IR & $3.9 \pm 1.5$ & $5.9 \pm 3.7$ & 0.029 \\
Triglyceride $(\mathrm{mmol} / \mathrm{L})$ & $4.0 \pm 7.1$ & $2.5 \pm 1.1$ & 0.812 \\
Total cholesterol $(\mathrm{mmol} / \mathrm{L})$ & $5.5 \pm 1.6$ & $5.0 \pm 0.7$ & 0.393 \\
LDL cholesterol $(\mathrm{mmol} / \mathrm{L})$ & $3.3 \pm 0.9$ & $3.2 \pm 0.6$ & 0.486 \\
HDL cholesterol $(\mathrm{mmol} / \mathrm{L})$ & $1.0 \pm 0.2$ & $1.0 \pm 0.2$ & 0.568 \\
Serum creatinine & $81.4 \pm 12.9$ & $81.2 \pm 16.9$ & 0.887 \\
AST (U/L) & $28.7 \pm 10.4$ & $34.4 \pm 11.4$ & 0.081 \\
ALT (U/L) & $40 \pm 17$ & $48 \pm 21$ & 0.241 \\
CRP (mg/L) & $3.5 \pm 4.8$ & $2.2 \pm 2.0$ & 0.558 \\
BDNF (ng/ml) & $43.7 \pm 7.5$ & $37.2 \pm 6.8$ & 0.011 \\
Zung SDS & $37.3 \pm 7.1$ & $38.0 \pm 10.4$ & 0.646 \\
\hline
\end{tabular}

${ }^{1}$ cutoff value: median (16.1\%) of the change percentage of BDNF. $\mathrm{ALT}=$ alanine aminotransferase, $\mathrm{AST}=$ aspartate aminotransferase, $\mathrm{BDNF}=$ brain-derived neurotrophic factor, $\mathrm{BMI}=$ body mass index, $\mathrm{BP}=$ blood pressure, $\mathrm{CRP}=\mathrm{C}$-reactive protein, $\mathrm{HDL}=$ high-density lipoprotein, HOMA-IR = homeostasis model assessment of insulin resistance, LDL = low-density lipoprotein, Zung SDS = Zung Self-Rating Depression Scale.

(Table 4). Furthermore, baseline BDNF seemed to be higher in the minor BDNF change group than in the other. However, after adjusting for the baseline BDNF levels, the change in BDNF was still associated with the reduction in Zung SDS (95\% confidence interval between -0.355 and 0.073, $\mathrm{P}=0.004)$.

\section{Discussion}

In the present study, lifestyle intervention by diet control and exercise promotion resulted in a significant body-weight reduction in men with MetS. BDNF was significantly increased after the weight-reduction program. However, the mean severity of depressive symptoms assessed by the Zung SDS did not significantly improve. An important finding of the present study was an inverse correlation between the changes in Zung SDS and circulating BDNF level. Our results showed the important role played by BDNF in improving depressive symptoms in men with MetS during the weight-reduction process. Nevertheless, the correlation between the reduction in 
Table 2 Alteration in clinical data of subjects grouped based on percentage change in BDNF

\begin{tabular}{|c|c|c|c|}
\hline & $\begin{array}{l}\text { Minor BDNF } \\
\text { change } \\
(n=18)\end{array}$ & $\begin{array}{c}\text { Greater BDNF } \\
\text { increase } \\
(n=18)\end{array}$ & $\mathbf{P}$ \\
\hline Body weight (kg) & $-7.7 \pm 4.8^{*}$ & $-9.1 \pm 5.4^{*}$ & \\
\hline (\%) & $-8.2 \% \pm 5.2 \%$ & $-9.2 \% \pm 5.2 \%$ & 0.752 \\
\hline Waist circumference $(\mathrm{cm})$ & $-9.3 \pm 5.9^{*}$ & $-10.0 \pm 5.8^{*}$ & \\
\hline (\%) & $-8.5 \% \pm 5.1 \%$ & $-9.0 \% \pm 5.3 \%$ & 0.812 \\
\hline Systolic BP (mmHg) & $-10 \pm 18^{*}$ & $-20 \pm 22^{*}$ & \\
\hline (\%) & $-6.6 \% \pm 12.9 \%$ & $-13.6 \% \pm 13.7 \%$ & 0.129 \\
\hline Diastolic BP (mmHg) & $-5 \pm 8^{*}$ & $-10 \pm 12^{*}$ & \\
\hline (\%) & $-6.4 \% \pm 9.1 \%$ & $-11.1 \% \pm 14.1 \%$ & 0.223 \\
\hline Fasting glucose (mmol/L) & $-0.2 \pm 0.5$ & $-0.4 \pm 0.6^{*}$ & \\
\hline (\%) & $-2.2 \% \pm 8.7 \%$ & $-5.9 \% \pm 10.9 \%$ & 0.159 \\
\hline HOMA IR & $-1.0 \pm 1.0^{*}$ & $-2.3 \pm 3.3^{*}$ & \\
\hline (\%) & $-24.4 \% \pm 19.6 \%$ & $-31.9 \% \pm 32.1 \%$ & 0.229 \\
\hline Triglyceride (mmol/L) & $-1.5 \pm 3.2^{*}$ & $-0.8 \pm 0.9^{*}$ & \\
\hline (\%) & $-32.3 \% \pm 21.5 \%$ & $-30.9 \% \pm 28.1 \%$ & 0.752 \\
\hline Total cholesterol (mmol/L) & $-0.6 \pm 0.9^{*}$ & $-0.1 \pm 0.6^{*}$ & \\
\hline (\%) & $-8.3 \% \pm 13.5 \%$ & $-3.0 \% \pm 11.2 \%$ & 0.164 \\
\hline LDL cholesterol (mmol/L) & $-0.4 \pm 0.5^{*}$ & $-0.1 \pm 0.6$ & \\
\hline (\%) & $-8.5 \% \pm 18.0 \%$ & $-2.1 \% \pm 18.2 \%$ & 0.206 \\
\hline HDL cholesterol (mmol/L) & $0.1 \pm 0.1$ & $0.1 \pm 0.3$ & \\
\hline (\%) & $8.8 \% \pm 15.2 \%$ & $8.4 \% \pm 25.0 \%$ & 0.899 \\
\hline Serum creatinine & $-4.5 \pm 8.2^{*}$ & $1.6 \pm 17.7$ & \\
\hline (\%) & $-5.2 \% \pm 9.2 \%$ & $2.2 \% \pm 18.0 \%$ & 0.056 \\
\hline AST (U/L) & $-7 \pm 10^{*}$ & $-11 \pm 10^{*}$ & \\
\hline (\%) & $-17.0 \% \pm 25.0 \%$ & $-28.1 \% \pm 24.1 \%$ & 0.129 \\
\hline $\mathrm{ALT}(\mathrm{U} / \mathrm{L})$ & $-12 \pm 14^{*}$ & $-19 \pm 13^{*}$ & \\
\hline (\%) & $-25.6 \% \pm 27.6 \%$ & $-36.8 \% \pm 19.6 \%$ & 0.248 \\
\hline CRP (mg/L) & $-1.7 \pm 4.7^{*}$ & $-0.7 \pm 2.1$ & \\
\hline (\%) & $-15.9 \% \pm 78.1 \%$ & $-1.6 \% \pm 60.3 \%$ & 0.343 \\
\hline BDNF (ng/ml) & $0.7 \pm 1.9$ & $5.7 \pm 2.2^{*}$ & \\
\hline (\%) & $3.2 \% \pm 8.8 \%$ & $31.3 \% \pm 12.4 \%$ & $<0.001$ \\
\hline Zung SDS & $2.3 \pm 6.7$ & $-3.9 \pm 6.2^{*}$ & \\
\hline (\%) & $8.8 \% \pm 23.9 \%$ & $-7.8 \% \pm 13.9 \%$ & 0.009 \\
\hline
\end{tabular}

${ }^{*}$ means $\mathrm{P}$ value less than 0.05 intra group.

1 cutoff value: median (16.1\%) of the change percentage of BDNF. $\mathrm{ALT}=$ alanine aminotransferase, $\mathrm{AST}=$ aspartate aminotransferase, $\mathrm{BDNF}=$ brain-derived neurotrophic factor, $\mathrm{BP}=$ blood pressure, $\mathrm{CRP}=\mathrm{C}$-reactive protein, $\mathrm{HDL}=$ high-density lipoprotein, $\mathrm{HOMA}-\mathrm{IR}=$ homeostasis model assessment of insulin resistance, $\mathrm{LDL}=$ low-density lipoprotein, $\mathrm{Pc}=$ post-challenge, Zung SDS = Zung Self-Rating Depression Scale.

body weight and change in BDNF was not significant in the present study. In fact, serum BDNF was not associated with fat components of the body [35]. Exercise training without significant body-weight reduction can also increase the circulating BDNF concentration [36,37]. It has been reported recently that only muscle-strengthening, but not aerobic exercise, could increase circulating BDNF levels in women [38]. However, the response of BDNF to exercise might differ between genders [39], and circulating BDNF levels might be greater after aerobic exercise, rather than muscle strengthening, in men [40]. Although serum BDNF change might be correlated with weight-reduction magnitude in subjects being treated for schizophrenia [41], the relationship between BDNF and body-weight might be different due to the influence of gender and antipsychotic treatment $[32,42]$. It has been postulated that the main response of BDNF to exercise originates in the central nervous system rather than adipose tissue $[43,44]$. Therefore, based on our findings, the alteration in BDNF might not be directly related to the magnitude of weight reduction in obese men. It has also been reported that only weight reduction was not capable of improving depressive symptoms [45].

The proportion of MetS was reported to be significantly higher in Asian men with depressive symptoms assessed by Zung SDS than in those without [46]. However, depressive severity might not be significantly altered with a $5 \%$ reduction in body weight, and may worsen with an advanced body-weight reduction of $10 \%$ [47]. It was also hypothesized that depression at baseline might hinder the effect of lifestyle intervention on weight reduction [48]. However, this hypothesis was not supported in a previous study on female subjects [49]. Recent data from the Look Action for Health in Diabetes (Look AHEAD) study, a large-scale study on lifestyle intervention, reported that baseline depressive symptoms did not attenuate the magnitude of weight reduction in subjects with Type 2 diabetes [50]. In the present study, neither the baseline condition nor the change in Zung SDS was correlated with the change in body weight. Our findings suggest that depressive symptoms do not attenuate the effect of lifestyle intervention, with a mean weight reduction of $8.7 \%$ in men with MetS.

Among the baseline characteristics assessed in the present study, only fasting insulin and insulin resistance (presented by HOMA-IR) were significantly associated with increase in BDNF. According to previous cross-sectional studies, insulin sensitivity was associated with circulating BDNF [30,51], and hyperinsulinemia was a risk factor for depression [15,52]. Although HOMA-IR was significantly improved at the end of the present study, the alteration in HOMA-IR was not significantly different between the group with a greater BDNF increase and the other. Neither fasting insulin nor HOMA-IR was significantly correlated with a reduction in Zung SDS after lifestyle intervention. The reduction in circulating insulin did not appear to appreciably improve depressive symptoms even with functional receptors expressed in the central nervous system [53]. Based on the other baseline parameters, 


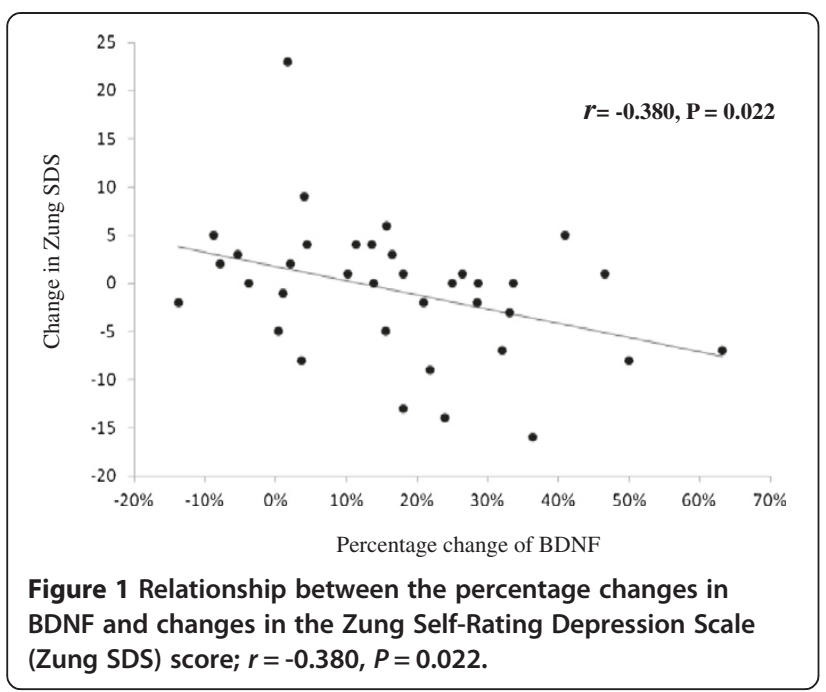

the alterations in BDNF and Zung SDS were not significantly different between the subjects with higher fasting glucose $(\geq 5.6 \mathrm{mmol} / \mathrm{L})$ and those with normal fasting glucose $(<5.6 \mathrm{mmol} / \mathrm{L})$ in the present study. Furthermore, the alterations in BDNF and Zung SDS were not significantly different between the subjects with higher ( $\geq$ median of 36.5) and lower $(<36.5)$ baseline Zung SDS. The alterations in Zung SDS and body weight were not significantly different between

\section{Table 3 Correlations between change in Zung SDS and percentage change based on different variables after body weight reduction}

\begin{tabular}{lcc}
\hline & $\boldsymbol{r}$ & $\mathbf{P}$ \\
\hline Body weight (\%) & 0.14 & 0.414 \\
Waist circumference (\%) & 0.15 & 0.382 \\
Systolic BP (\%) & 0.19 & 0.261 \\
Diastolic BP (\%) & 0.19 & 0.279 \\
Fasting glucose (\%) & -0.11 & 0.540 \\
Fasting insulin (\%) & 0.09 & 0.599 \\
HOMA IR (\%) & 0.04 & 0.810 \\
Total cholesterol (\%) & -0.26 & 0.128 \\
Triglyceride (\%) & 0.06 & 0.736 \\
HDL cholesterol (\%) & -0.19 & 0.267 \\
LDL cholesterol (\%) & 0.19 & 0.270 \\
Serum creatinine (\%) & -0.20 & 0.232 \\
AST (\%) & 0.02 & 0.907 \\
ALT (\%) & 0.08 & 0.641 \\
CRP (\%) & -0.09 & 0.621 \\
\hline ALT
\end{tabular}

$\mathrm{ALT}=$ alanine aminotransferase, $\mathrm{AST}=$ aspartate aminotransferase, $\mathrm{BDNF}=$ brain-derived neurotrophic factor, $\mathrm{BP}=$ blood pressure, $\mathrm{CRP}=\mathrm{C}$-reactive protein, $\mathrm{HDL}=$ high-density lipoprotein, HOMA-IR = homeostasis model assessment of insulin resistance, $\mathrm{LDL}=$ low-density lipoprotein, Zung SDS = Zung Self-Rating Depression Scale.
Table 4 Effects of risk factors on the changes in Zung Self-Rating Depression Scale during the study

\begin{tabular}{lccccc}
\hline & $\boldsymbol{\beta}^{\mathbf{1}}$ & $\mathbf{B}^{\mathbf{2}}$ & $\mathbf{9 5 \%} \mathbf{C l}$ & $\mathbf{P}$ \\
\hline Baseline & & & & & \\
Age (years) & 0.154 & 0.102 & -0.115 & 0.319 & 0.346 \\
HOMA-IR & 0.249 & 0.592 & -0.167 & 1.350 & 0.122 \\
$\begin{array}{l}\text { Change } \\
\text { Body weight (\%) }\end{array}$ & 0.209 & 0.286 & -0.155 & 0.728 & 0.196 \\
BDNF (\%) & -0.461 & -0.184 & -0.315 & -0.052 & 0.008 \\
\hline
\end{tabular}

${ }^{1} \beta=$ standardized coefficient, ${ }^{2} B=$ linear regression coefficient, $B D N F=$ brain-derived neurotrophic factor, $\mathrm{CRP}=\mathrm{C}$-reactive protein, $\mathrm{HOMA}-\mathrm{IR}=$ homeostasis model assessment of insulin resistance.

the subjects with higher ( $\geq$ median of $40.7 \mathrm{ng} / \mathrm{ml}$ ) and lower one $(\mathrm{BDNF}<40.7 \mathrm{ng} / \mathrm{ml})$ baseline BDNF. In addition, our results showed that Zung SDS was not significantly correlated with inflammation.

Our study shows that the increase in BDNF was inversely correlated with the severity of depressive symptoms in men without psychological disorders. Despite the confounding effect from the open-label questionnaire answers, the study participants and the investigators were blinded to the BDNF data during the study. This finding is noteworthy because BDNF was found to be involved in the pathogenic mechanism of depression [44,54]. However, the motivation of enrolled subjects in a short-term study is usually expected to be stronger, and the effects of body-weight reduction may be greater than those in a long-term follow-up. In the Look AHEAD study, an astonishing reduction in cardiovascular risks was observed within the first year, but the benefits were gradually attenuated in the following years $[55,56]$. With a median follow-up of approximately 10 years, cardiovascular events were not significantly reduced in the Look AHEAD study [57]. Therefore, further study on the long-term effects of lifestyle intervention on BDNF and depression are warranted.

There were several limitations in the present study. First, the postprandial change in BDNF by meal test was not assessed. An increase in free fatty acid was recently reported to suppress circulating BNDF after a high-fat intake [58]. However, it was unclear whether the response of BDNF to fat intake was associated with the depressive symptoms after body weight reduction. Second, our findings should only be applied to men. It has recently been reported that the relationship between circulating BDNF level and body weight differs between men and women [59]. There seemed to be a gender difference in the response of BDNF and depression to body-weight reduction [32]. Third, the men with increased BDNF showed a significant decrease in Zung SDS. The assessment of BDNF appeared to demonstrate that lifestyle intervention had an effect on depression. However, based on the 
present data, it is unclear whether a BDNF supplement would ameliorate depressive symptoms or affect body weight. In addition, cognitive functions or other psychological disorders were not assessed in the present study. In consideration of the pleiotropic effects of BDNF $[60,61]$, it is possible that there were more psychological benefits for those subjects with increased BDNF after lifestyle intervention. It has been reported that low BDNF could predict high mortality in women [62], but its predictive ability in men requires further long-term studies.

In conclusion, after a 12-week weight reduction program, a decrease in body weight increased serum BDNF in obese men with MetS. However, depressive symptoms, as assessed by Zung SDS, were only significantly improved in subjects with increased serum BDNF levels after lifestyle intervention, independent of changes in body weight.

\begin{abstract}
Abbreviations
ALT: Alanine aminotransferase; AST: Aspartate aminotransferase; BDNF: Brain-derived neurotrophic factor; BMI: Body mass index; CRP: C-reactive protein; HDL: High-density lipoprotein; HOMA-IR: Homeostasis model assessment of insulin resistance; IDF: International Diabetes Federation; LDL: Low-density lipoprotein; MetS: Metabolic syndrome; SD: Standard deviation; Zung SDS: Zung Self-Rating Depression Scale.
\end{abstract}

\section{Competing interests}

The authors declare that they have no competing interests.

\section{Authors' contributions}

I-TL conducted the study, interpreted the data and wrote the manuscript; C-PF conducted the study; W-JL conducted the study, performed the data collection and analysis; K-WL, S-YL, C-JW conducted the study; and WH-HS conducted the study, interpreted the data and wrote the manuscript. All authors read and approved the final manuscript.

\section{Acknowledgements}

The work was supported by grants from Taichung Veterans General Hospital, Taichung, Taiwan, R.O.C. (TCVGH-1023504C, TCVGH-PU1018101, TCVGH-983502A) and the National Science Council, Taiwan, (NSC 102-2314-B-075A-001).

\section{Author details}

'Division of Endocrinology and Metabolism, Department of Internal Medicine, Taichung Veterans General Hospital, No. 1650, Section 4, Taiwan Boulevard, Taichung 40705, Taiwan. ${ }^{2}$ School of Medicine, Chung Shan Medical University, Taichung, Taiwan. ${ }^{3}$ School of Medicine, National Yang-Ming University, Taipei, Taiwan. ${ }^{4}$ Department of Medical Research, Taichung Veterans General Hospital, Taichung, Taiwan. ${ }^{5}$ Cardiovascular Center, Taichung Veterans General Hospital, Taichung, Taiwan. ${ }^{6}$ Department of Nutrition, Hung-Kuang University, Taichung, Taiwan. ${ }^{7}$ Institute of Medical Technology, National Chung-Hsing University, Taichung, Taiwan.

Received: 30 July 2013 Accepted: 11 February 2014

Published: 13 February 2014

\section{References}

1. National Cholesterol Education Program: Executive Summary of The Third Report of The National Cholesterol Education Program (NCEP) expert panel on detection, evaluation, and treatment of high blood cholesterol in adults (Adult Treatment Panel III). JAMA 2001, 285(19):2486-2497.

2. Sattar N, Gaw A, Scherbakova O, Ford I, O'Reilly DS, Haffner SM, Isles C, Macfarlane PW, Packard CJ, Cobbe SM, et al: Metabolic syndrome with and without C-reactive protein as a predictor of coronary heart disease and diabetes in the West of Scotland Coronary Prevention Study.

Circulation 2003, 108(4):414-419.
3. Cornier MA, Dabelea D, Hernandez TL, Lindstrom RC, Steig AJ, Stob NR, Van Pelt RE, Wang H, Eckel RH: The metabolic syndrome. Endocrine reviews 2008, 29(7):777-822.

4. Zimmet $P$, Magliano D, Matsuzawa Y, Alberti G, Shaw J: The metabolic syndrome: a global public health problem and a new definition. J Atherosclerosis Thromb 2005, 12(6):295-300.

5. Despres JP, Lemieux I: Abdominal obesity and metabolic syndrome. Nature 2006, 444(7121):881-887.

6. Lee IT, Lee WJ, Huang CN, WHHS: The association of low-grade inflammation, urinary albumin, and insulin resistance with metabolic syndrome in nondiabetic Taiwanese. Metabolism 2007, 56(12):1708-1713.

7. Tuomilehto J, Lindstrom J, Eriksson JG, Valle TT, Hamalainen H, llanne-Parikka P, Keinanen-Kiukaanniemi S, Laakso M, Louheranta A, Rastas M, et al: Prevention of type 2 diabetes mellitus by changes in lifestyle among subjects with impaired glucose tolerance. New Engl J Med 2001, 344(18):1343-1350.

8. Ashley FW Jr, Kannel WB: Relation of weight change to changes in atherogenic traits: the Framingham Study. J Chron Dis 1974, 27(3):103-114.

9. Brown T, Avenell A, Edmunds LD, Moore H, Whittaker V, Avery L, Summerbell C: Systematic review of long-term lifestyle interventions to prevent weight gain and morbidity in adults. Obes Rev 2009, 10(6):627-638.

10. Melville CA, Hamilton S, Hankey CR, Miller S, Boyle S: The prevalence and determinants of obesity in adults with intellectual disabilities. Obes Rev 2007, 8(3):223-230

11. Jagust W, Harvey D, Mungas D, Haan M: Central obesity and the aging brain. Arch Neurol 2005, 62(10):1545-1548

12. Yaffe K: Metabolic syndrome and cognitive decline. Curr Alzheimer Res 2007, 4(2):123-126.

13. Yaffe K, Kanaya A, Lindquist K, Simonsick EM, Harris T, Shorr Rl, Tylavsky FA, Newman $A B$ : The metabolic syndrome, inflammation, and risk of cognitive decline. JAMA 2004, 292(18):2237-2242.

14. Noble JM, Manly JJ, Schupf N, Tang MX, Mayeux R, Luchsinger JA: Association of C-reactive protein with cognitive impairment. Arch Neurol 2010, 67(1):87-92.

15. Benoit SC, Clegg DJ, Seeley RJ, Woods SC: Insulin and leptin as adiposity signals. Recent Progr Horm Res 2004, 59:267-285

16. Luchsinger JA, Mayeux R: Adiposity and Alzheimer's disease. Curr Alzheimer Res 2007, 4(2):127-134.

17. Milionis HJ, Florentin M, Giannopoulos S: Metabolic syndrome and Alzheimer's disease: a link to a vascular hypothesis? CNS spectrums 2008 13(7):606-613.

18. Lebrun B, Bariohay B, Moyse E, Jean A: Brain-derived neurotrophic factor (BDNF) and food intake regulation: a minireview. (Auton Neurosci: basic \& clinical 2006, 126-127:30-38.

19. Leibrock J, Lottspeich F, Hohn A, Hofer M, Hengerer B, Masiakowski P, Thoenen $\mathrm{H}$, Barde $\mathrm{YA}$ : Molecular cloning and expression of brain-derived neurotrophic factor. Nature 1989, 341(6238):149-152

20. Rosenfeld RD, Zeni L, Haniu M, Talvenheimo J, Radka SF, Bennett L, Miller JA, Welcher AA: Purification and identification of brain-derived neurotrophic factor from human serum. Protein Expr Purif 1995, 6(4):465-471.

21. Pan W, Banks WA, Fasold MB, Bluth J, Kastin AJ: Transport of brain-derived neurotrophic factor across the blood-brain barrier. Neuropharmacology 1998, 37(12):1553-1561.

22. Yamada $K$, Mizuno M, Nabeshima $T$ : Role for brain-derived neurotrophic factor in learning and memory. Life Sciences 2002, 70(7):735-744.

23. Fernandes BS, Gama CS, Kauer-Sant'Anna M, Lobato MI, Belmonte-de-Abreu P, Kapczinski F: Serum brain-derived neurotrophic factor in bipolar and unipolar depression: a potential adjunctive tool for differential diagnosis. (J Psychiatr Res 2009, 43(15):1200-1204.

24. Brunoni AR, Lopes M, Fregni F: A systematic review and meta-analysis of clinical studies on major depression and BDNF levels: implications for the role of neuroplasticity in depression. Int J Neuropsychopharmacol 2008, 11(8):1169-1180.

25. Toriya M, Maekawa F, Maejima Y, Onaka T, Fujiwara K, Nakagawa T, Nakata M, Yada T: Long-term infusion of brain-derived neurotrophic factor reduces food intake and body weight via a corticotrophin-releasing hormone pathway in the paraventricular nucleus of the hypothalamus. J Neuroendocrinol 2010, 22(9):987-995.

26. Nakagawa $T$, Tsuchida A, Itakura $Y$, Nonomura $T$, Ono M, Hirota F, Inoue $T$, Nakayama C, Taiji M, Noguchi H: Brain-derived neurotrophic factor regulates glucose metabolism by modulating energy balance in diabetic mice. Diabetes 2000, 49(3):436-444 
27. Suwa M, Kishimoto H, Nofuji Y, Nakano H, Sasaki H, Radak Z, Kumagai S: Serum brain-derived neurotrophic factor level is increased and associated with obesity in newly diagnosed female patients with type 2 diabetes mellitus. Metabol Clin Exp 2006, 55(7):852-857.

28. Golden E, Emiliano A, Maudsley S, Windham BG, Carlson OD, Egan JM, Driscoll I, Ferrucci L, Martin B, Mattson MP: Circulating brain-derived neurotrophic factor and indices of metabolic and cardiovascular health: data from the Baltimore Longitudinal Study of Aging. PLos One 2010, 5(4):e10099.

29. Levinger I, Goodman C, Matthews V, Hare DL, Jerums G, Garnham A, Selig S: BDNF, metabolic risk factors, and resistance training in middle-aged individuals. Med Sci Sports Exerc 2008, 40(3):535-541.

30. Krabbe KS, Nielsen AR, Krogh-Madsen R, Plomgaard P, Rasmussen $P$, Erikstrup C, Fischer CP, Lindegaard B, Petersen AM, Taudorf S, et al: Brain-derived neurotrophic factor (BDNF) and type 2 diabetes. Diabetologia 2007, 50(2):431-438

31. Chaldakov GN, Fiore M, Stankulov IS, Hristova M, Antonelli A, Manni L, Ghenev PI, Angelucci F, Aloe L: NGF, BDNF, leptin, and mast cells in human coronary atherosclerosis and metabolic syndrome. Arch Physio Biochem 2001, 109(4):357-360.

32. Martin B, Pearson M, Kebejian L, Golden E, Keselman A, Bender M, Carlson O, Egan J, Ladenheim B, Cadet JL, et al: Sex-dependent metabolic neuroendocrine, and cognitive responses to dietary energy restriction and excess. Endocrinology 2007, 148(9):4318-4333.

33. Zung WW: A Self-Rating Depression Scale. Arch Gen Psychiatr 1965, 12:63-70.

34. Matthews DR, Hosker JP, Rudenski AS, Naylor BA, Treacher DF, Turner RC: Homeostasis model assessment: insulin resistance and beta-cell function from fasting plasma glucose and insulin concentrations in man. Diabetologia 1985, 28(7):412-419.

35. Lee IT, Lee WJ, Tsai IC, Liang KW, Lin SY, Wan CJ, Fu CP, Sheu WH: Brain-derived neurotrophic factor not associated with metabolic syndrome but inversely correlated with vascular cell adhesion molecule-1 in men without diabetes. Clin Chim Acta 2012, 413(9-10):944-948.

36. Pedersen BK, Pedersen M, Krabbe KS, Bruunsgaard H, Matthews VB, Febbraio MA: Role of exercise-induced brain-derived neurotrophic factor production in the regulation of energy homeostasis in mammals. Exp Physiol 2009, 94(12):1153-1160

37. Zoladz JA, Pilc A, Majerczak J, Grandys M, Zapart-Bukowska J, Duda K: Endurance training increases plasma brain-derived neurotrophic factor concentration in young healthy men. J Physiol Pharmacol 2008, 59(Suppl 7):119-132.

38. Pereira DS, de Queiroz BZ, Miranda AS, Rocha NP, Felicio DC, Mateo EC, Favero M, Coelho FM, Jesus-Moraleida F, Gomes Pereira DA, et al: Effects of physical exercise on plasma levels of brain-derived neurotrophic factor and depressive symptoms in elderly women-a randomized clinical trial. Arch Phys Med Rehabil 2013, 94(8):1443-1450.

39. Schmidt-Kassow M, Schadle S, Otterbein S, Thiel C, Doehring A, Lotsch J, Kaiser J: Kinetics of serum brain-derived neurotrophic factor following low-intensity versus high-intensity exercise in men and women. Neuroreport 2012, 23(15):889-893.

40. Baker LD, Frank LL, Foster-Schubert K, Green PS, Wilkinson CW, McTiernan A, Plymate SR, Fishel MA, Watson GS, Cholerton BA, et al: Effects of aerobic exercise on mild cognitive impairment: a controlled trial. Arch Neurol 2010, 67(1):71-79.

41. Kuo FC, Lee CH, Hsieh CH, Kuo P, Chen YC, Hung YJ: Lifestyle modification and behavior therapy effectively reduce body weight and increase serum level of brain-derived neurotrophic factor in obese non-diabetic patients with schizophrenia. Psychiatr Res 2013, 209(2):150-154

42. Zai GC, Zai CC, Chowdhury NI, Tiwari AK, Souza RP, Lieberman JA Meltzer HY, Potkin SG, Muller DJ, Kennedy JL: The role of brain-derived neurotrophic factor (BDNF) gene variants in antipsychotic response and antipsychotic-induced weight gain. Progr Neuro Psychopharmacol Biol Psychiatr 2012, 39(1):96-101.

43. Rasmussen P, Brassard P, Adser H, Pedersen MV, Leick L, Hart E, Secher NH, Pedersen BK, Pilegaard H: Evidence for a release of brain-derived neurotrophic factor from the brain during exercise. Exp Physiol 2009, 94(10):1062-1069.

44. Martinowich K, Manji H, Lu B: New insights into BDNF function in depression and anxiety. Nat Neurosci 2007, 10(9):1089-1093.

45. Chaput JP, Drapeau V, Hetherington M, Lemieux S, Provencher V, Tremblay A: Psychobiological effects observed in obese men experiencing body weight loss plateau. Depress Anxiety 2007, 24(7):518-521.
46. Kamezaki F, Sonoda S, Nakata S, Okazaki M, Tamura M, Abe H, Takeuchi M, Otsuji Y: Elevated depressive symptoms are associated with hypertriglyceridemia in Japanese male workers. Intern Med 2011, 50(21):2485-2490.

47. Chaput JP, Drapeau V, Hetherington M, Lemieux S, Provencher V, Tremblay A: Psychobiological impact of a progressive weight loss program in obese men. Physiol Behav 2005, 86(1-2):224-232.

48. Pagoto S, Bodenlos JS, Kantor L, Gitkind M, Curtin C, Ma Y: Association of major depression and binge eating disorder with weight loss in a clinical setting. Obesity 2007, 15(11):2557-2559.

49. Ludman E, Simon GE, Ichikawa LE, Operskalski BH, Arterburn D, Linde JA, Jeffery RW, Rohde P, Finch EA: Does depression reduce the effectiveness of behavioral weight loss treatment? Behav Med 2010, 35(4):126-134.

50. Faulconbridge LF, Wadden TA, Rubin RR, Wing RR, Walkup MP, Fabricatore AN, Coday M, Van Dorsten B, Mount DL, Ewing LJ, et al: One-year changes in symptoms of depression and weight in overweight/obese individuals with type 2 diabetes in the Look AHEAD study. Obesity 2012, 20(4):783-793.

51. Karczewska-Kupczewska M, Straczkowski M, Adamska A, Nikolajuk A, Otziomek E, Gorska M, Kowalska I: Decreased serum brain-derived neurotrophic factor concentration in young nonobese subjects with low insulin sensitivity. Clin Biochem 2011, 44(10-11):817-820.

52. Lechin F, van der Dijs B: Central nervous system circuitry involved in the hyperinsulinism syndrome. Neuroendocrinology 2006, 84(4):222-234.

53. Kleinridders A, Konner AC, Bruning JC: CNS-targets in control of energy and glucose homeostasis. Curr Opin Pharmacol 2009, 9(6):794-804.

54. Shimizu E, Hashimoto K, Okamura N, Koike K, Komatsu N, Kumakiri C, Nakazato M, Watanabe H, Shinoda N, Okada S, et al: Alterations of serum levels of brain-derived neurotrophic factor (BDNF) in depressed patients with or without antidepressants. Biol Psychiatr 2003, 54(1):70-75.

55. Redmon JB, Bertoni AG, Connelly S, Feeney PA, Glasser SP, Glick H, Greenway F, Hesson LA, Lawlor MS, Montez M, et al: Effect of the look AHEAD study intervention on medication use and related cost to treat cardiovascular disease risk factors in individuals with type 2 diabetes. Diabetes Care 2010, 33(6):1153-1158.

56. Rubin RR, Peyrot M, Gaussoin SA, Espeland MA, Williamson D, Faulconbridge LF, Wadden TA, Ewing L, Safford M, Evans-Hudnall G, et al: Four-year analysis of cardiovascular disease risk factors, depression symptoms, and antidepressant medicine use in the Look AHEAD (Action for Health in Diabetes) clinical trial of weight loss in diabetes. Diabetes Care 2013, 36(5):1088-1094.

57. Look ARG, Wing RR, Bolin P, Brancati FL, Bray GA, Clark JM, Coday M, Crow RS, Curtis JM, Egan CM, et al: Cardiovascular effects of intensive lifestyle intervention in type 2 diabetes. New Engl J Med 2013, 369(2):145-154.

58. Karczewska-Kupczewska M, Kowalska I, Nikolajuk A, Adamska A, Zielinska M, Kaminska N, Otziomek E, Gorska M, Straczkowski M: Circulating brain-derived neurotrophic factor concentration is downregulated by intralipid/heparin infusion or high-fat meal in young healthy male subjects. Diabetes Care 2012, 35(2):358-362.

59. Pillai A, Bruno D, Sarreal AS, Hernando RT, Saint-Louis LA, Nierenberg لـ Ginsberg SD, Pomara N, Mehta PD, Zetterberg H, et al: Plasma BDNF levels vary in relation to body weight in females. PloS One 2012, 7(7):e39358.

60. Hashimoto K, Shimizu E, lyo M: Critical role of brain-derived neurotrophic factor in mood disorders. Brain Res Rev 2004, 45(2):104-114.

61. Hashimoto K: Brain-derived neurotrophic factor as a biomarker for mood disorders: an historical overview and future directions. Psychiatr Clin Neurosci 2010, 64(4):341-357.

62. Krabbe KS, Mortensen EL, Avlund K, Pedersen AN, Pedersen BK, Jorgensen T, Bruunsgaard $\mathrm{H}$ : Brain-derived neurotrophic factor predicts mortality risk in older women. J Am Geriatr Soc 2009, 57(8):1447-1452.

doi:10.1186/1758-5996-6-18

Cite this article as: Lee et al:: Brain-derived neurotrophic factor, but not body weight, correlated with a reduction in depression scale scores in men with metabolic syndrome: a prospective weight-reduction study. Diabetology \& Metabolic Syndrome 2014 6:18. 